SILVA, Juliana Catarine Barbosa da, MENEZES, Jaileila de Araújo. O risco de desastre e as cidades...

\title{
O risco de desastre e as cidades: uma análise discursiva sobre prá- ticas em defesa civil
}

\author{
The disaster risk and the cities: a discursive analysis of practices in \\ civil defense
}

http://dx.doi.org/10.5007/2178-4582.2016v50n2p528

Juliana Catarine Barbosa da Silva

Jaileila de Araújo Menezes

Universidade Federal de Pernambuco, Recife/PE, Brasil

\begin{abstract}
O presente artigo, utilizando uma metodologia qualitativa de análise do discurso, buscou compreender e discutir o modelo de risco de desastre que fundamenta algumas práticas em defesa civil no Brasil. Para isso, foi realizado um breve levantamento crítico da história da defesa civil no país e foram analisados o Plano Nacional de Gestão de Risco e Resposta a Desastres Naturais 20122014 e a Política Nacional de Proteção e Defesa Civil - lei federal 12.608/2012. Em nosso estudo encontramos um modelo de risco de desastres que fundamenta suas ações no gerenciamento de desastres naturais, em detrimento do debate sobre as vulnerabilidades sociais. Ressaltamos que os processos de urbanização atuais levaram pessoas pobres a habitar as periferias das grandes cidades, desenvolvendo um ordenamento territorial que as encurrala em áreas de risco que são naturalizadas, ou seja, as intercorrências que ali se dão são em sua maioria tratadas como desastres naturais.
\end{abstract}

Palavras-chave: Risco de desastres; Biopolítica; Defesa civil e cidades.
To achieve this, referring to a qualitative methodology for discourse analysis, a brief critical study of civil defense history in the country was done and the National Plan for Risk Management and Response to Natural Disasters were analyzed, launched by the federal government as proposals for action for 2012-2014, as well as federal law 12.608/2012 which treats National Policy for Protection and Civil Defense. Throughout the article we sought to debate how the discourse on disaster risk, in the national context of Protection and Civil Defense, bases its lines of action on the management of "natural" disasters, to the detriment of about social vulnerability debate. This is to highlight that current processes of urbanization have lead poor people to inhabit the peripheries of large cities, developing a territorial hierarchy which traps them in areas at risk which are so naturalized that the complications found there are, for the most part, treated as natural disasters.

Keywords: Disaster risk, Biopolitcs, Civil defense and cities.

\section{Introdução}

O presente texto objetiva compreender e debater o modelo de risco de desastre presente em alguns documentos que marcam as linhas de ação para as atividades em defesa civil no Brasil. Para isso foi realizado um breve levantamento crítico da história da defesa civil no país e foram analisados o Plano Nacional de Gestão de Risco e Resposta a Desastres Naturais, lançado pelo governo federal como propostas de ações para 2012-2014 e a Lei Federal no 12.608/2012 que trata da Política Nacional de Proteção e Defesa Civil - PNPDEC. O estudo apresentado aqui faz parte de uma pesquisa maior, 
ainda em andamento, realizada como proposta de tese em um Programa de Pós-graduação em Psicologia.

Mais de 226 milhões de pessoas são afetadas por desastres, a cada ano em todo o mundo. Os fatores que acentuam o aumento do número de pessoas vulneráveis aos desastres estão relacionados ao crescimento populacional, o grande impacto das mudanças climáticas, a pobreza, o aumento da urbanização com falhas de planejamento, a falta de gestão no ordenamento territorial e a degradação dos ecossistemas (CEPEDES/FIOCRUZ, 2013, p. 5).

Entre 1970 e 2010, a proporção da população que vive em bacias hidrográficas sujeitas a inundações aumentou $114 \%$; já nas regiões costeiras expostas a ciclones, o aumento foi de $192 \%$. Enfatiza-se ainda que a elevada densidade populacional representa um condutor do risco, na qual a qualidade das moradias, a infraestrutura e os serviços são deficientes (CEPEDES/ FIOCRUZ, 2013, p. 5).

Valencio, Siena, Marchezine, e Gonçalves (2009, p. 199) destacam que o modo como as pessoas compreendem e se relacionam com as situações de risco, interfere diretamente na forma como se comportarão diante de situações perigosas. Nesse sentido, os meios de acesso democrático à informação, recursos materiais e tecnológicos são fundamentais para combater as desigualdades que são visibilizadas e acentuadas pela ocorrência de eventos adversos.

Mesmo a questão das emergências e desastres, principalmente aqueles classificados como naturais, não sendo uma problemática recente na história da humanidade, nos últimos anos vem ganhando bastante ênfase e sendo sistematicamente inserida nos universos acadêmico e midiático. Crescem o número de pesquisas que tentam problematizar o contexto do risco, ou mesmo buscar explicações para, apesar dos inúmeros avanços tecnológicos, a humanidade ainda estar tão despreparada para as catástrofes que nos atingem de forma regular e muitas vezes anunciada (CARDOSO; COSTA; NAVARRO, 2012, p. 1524 - 1530; MATTEDI, 2008, p. 164 - 171; ALVES; LACERDA; LEGAL, 2012, p. 308).

Ao entrarmos em contato com algumas dessas pesquisas, observamos como os termos que entrelaçam e contextualizam esse caminho são múltiplos e diversos. A palavra risco, por exemplo, assume uma gama de sentidos nos mais distintos contextos nos quais é utilizada, sendo fonte de estudos em variadas áreas.

Segundo o dicionário Aurélio (FERREIRA, 2013, p. 1764) risco pode ser definido como "perigo ou possibilidade de perigo; (...) situação em que há probabilidades mais ou menos previsíveis de perda ou ganho". Já no dicionário Larousse (1992, p. 990) encontramos as seguintes definições para a palavra 
risco: "Possibilidade de perigo; (...) acontecimento eventual incerto cuja ocorrência não depende da vontade dos interessados" . A partir da compreensão do termo risco podemos perceber as diversas possibilidades de uso do mesmo nos mais distintos contextos. Desse modo, fala-se dos riscos de contrair uma doença no contexto das ciências da saúde, fala-se do "Risco Brasil" na economia, fala-se de grupos de risco ou de populações em risco no serviço social, discute-se risco em muitas áreas do fazer e da produção de conhecimento.

Por isso, no presente texto, situado no contexto de debates sobre a defesa civil, utilizaremos o termo risco de desastres para delimitar e definir como as implicações desse termo circulam ao longo de alguns debates sobre defesa civil. Tal escolha foi reforçada por nossos estudos bibliográficos iniciais, ao realizarmos buscas em bases de dados com o objetivo de compreender as produções acadêmicas que a psicologia tem desenvolvido sobre o tema.

Observamos também, que na psicologia, a temática dos riscos de desastres tem percorrido os mais variados caminhos, existem teóricos(as) que se propõe a compreender a questão a partir de construtos mais cognitivistas, como percepção de risco, por exemplo (PAULINO; LOPES, 2010, p. 754-761); localizamos também pesquisadores(as) que focam os elementos clínicos relacionados à exposição de pessoas à situações de risco (FRANCO, 2005, p. 177179); outros(as) buscam ainda compreender o risco a partir das leituras em psicologia social, enfatizando compreensões socioculturais sobre a temática (SPINK; PEREIRA; BURIM; SILVA; DIODATO, 2008, p. 2-3). O presente artigo está enquadrado neste último grupo de debate.

$\mathrm{Na}$ psicologia social, termos como risco, percepção de risco e enfretamento ao risco ganham força quando o assunto é emergências e desastres. Quando associado ao referido contexto o risco está geralmente relacionado a danos físicos, psíquicos e materiais. Ressalta-se ainda que mesmo existindo uma tradição literária que diferencia os desastres em naturais, humanos ou mistos, é possível refletir que qualquer evento adverso pode ser considerado um desastre quando atinge um ecossistema vulnerável (CEPED, 2010, p. 21).

Para Valencio et al. (2009, p. 4, 5 e 20), tanto as Ciências Sociais quanto a Sociologia buscam problematizar a definição de "desastre natural", compreendendo que os mesmos não se apresentam, em sua maioria, como variáveis independentes e intrinsecamente relacionados somente aos fenômenos naturais, estando totalmente interligados a dinâmica social na qual ocorrem, possibilitando importantes reflexões sobre relações sociais, territoriais, institucionais, historicamente situadas.

Nesse sentido, dentre as distintas formas que podemos classificar os desastres destacamos a divisão entre intensivos e extensivos. Enquanto os primeiros se referem aos que possuem baixa frequência, mas são geograficamente con- 
centrados e com grande potencial de impacto, os segundos caracterizam-se por ocorrerem com maior frequência e provocarem menores danos. Os desastres extensivos correspondem a 97\% dos eventos relacionados ao clima, possuindo alta frequência, não causando números significativos de óbitos, porém são responsáveis por grande proporção de danos à infraestrutura local e às habitações e condições de vida das comunidades e sociedades mais pobres (FREITAS; CARVALHO; XIMENES; ARRAES; GOMES, 2012, p. 1578-1579).

Os desastres extensivos são facilmente incorporados a "normalidade" das idiossincrasias urbanas, tornando-se potencialmente perigosos ao passo que são encarados como inofensivos e naturais. No entanto, devido à falta de atenção e monitoramento, muitos desastres extensivos acabam desenvolvendo potenciais intensivos e causando desastres em grandes proporções, como o acontecido na região serrana do Rio de Janeiro em 2011 (FREITAS et al., 2012, p. 1579).

Os desastres extensivos, comuns em contextos urbanos que cresceram de forma desordenada e descoordenada, marcam a história de várias metrópoles no Brasil e no exterior. Em Recife e região metropolitana os deslizamentos de morros e encostas, assim como as situações de alagamentos, são exemplos de desastres extensivos que foram incorporados à realidade local.

Segundo dados do último Censo o Recife possui uma população de 1.537.704 habitantes dos quais 349.920 residem em áreas denominadas como aglomerados subnormais ou favelas, muito dos quais localizados em áreas de morros. A ocupação nas áreas de encostas é em sua maioria feita de forma desordenada, com baixo padrão construtivo e uso incorreto do solo, trazendo impactos ambientais, como erosões, ruptura de taludes e supressão da vegetação, provocando perda de solo de superfície e instabilidade de encostas, colaborando para a formação de uma série de riscos para a população que ali reside (CEPED, 2011, p. 47-49).

Como podemos observar a problemática do risco envolve uma serie de elementos para além da questão climática propriamente dita, as vulnerabilidades sociais, a exclusão social, a inexistência de políticas de distribuição de terras e renda são elementos que se destacam quando adentramos o estudo da situação de risco no Brasil. Contudo, como buscaremos expor ao longo do presente artigo, as políticas de Proteção e Defesa Civil nacionais, tendem a tratar os fatores climáticos como um dos grandes vilões no contexto das emergências e desastres, deixando em segundo plano a situação de miserabilidade e ausência de políticas públicas as quais a população pobre está exposta. Para que possamos fortalecer nossa linha de argumentação recorreremos a alguns conceitos desenvolvidos por Michel Foucault, que ao longo de suas obras explicita diversos modos de controle do Estado sobre os indivíduos e as populações. 


\section{Um olhar foucaultiano sobre as cidades}

Governo, população e território são três elementos que estão profundamente conectados, ocupar as ruas, circular pelo espaço público, ações aparentemente simples estão a todo o tempo sendo moldadas e reconfiguradas, sendo fortemente influenciadas pelos modelos de gestão das cidades.

Foucault (2010, p. 202) afirma que um dos fenômenos seminais do século XIX foi a reinscrição da vida pelo biopoder, demarca-se a leitura estatística dos aspectos biológicos.Para explicar a ideia posta em destaque, o autor volta à teoria clássica sobre soberania, que centrava no direito de vida e de morte uma de suas características fundamentais. Cabia ao soberano, representante de um tipo de poder identificado inicialmente nos séculos XII e XIII (FOUCAUT, 1993, p. 67), "fazer morrer e deixar viver". Tal análise proposta por Foucault inscreve a vida e a morte no plano político, para o soberano o efeito sobre a vida só se opera a partir do momento que ele tem o poder de matar, sendo o direito sobre a vida exercido na medida em que se exerce o direito sobre a morte.

Nos séculos XVII e XVIII destacam-se as tecnologias disciplinares, voltadas para o corpo individual e para a maximização de suas práticas. Tais técnicas que tratavam da distribuição das pessoas nos espaços, assim como de sua articulação para melhor produção, buscavam forjar corpos politicamente dóceis e economicamente úteis. Temos, no entanto no modelo que ascende no final do século XVIII e século XIX uma inversão na lógica do direito que vem a complementar o "velho direito de soberania" (FOUCAULT, 2010, p. 202), perpassando-o, penetrando-o e modificando-o, emerge o biopoder, com o direito de fazer viver ou deixar morrer. Tal forma de exercer o poder não exclui os modos anteriores, mas os complementa na ação sobre as populações (FOUCAULT, 2010, p. 202)

É a partir do século XVIII que o controle estatístico da população ganha foco, controla-se a quantidade de nascimentos, de óbitos, problemas econômicos, probabilidade de eventos adversos, instaura-se uma biopolítica das populações. Para Foucault (2010, p. 206) é nesse momento histórico que vemos acentuar-se a preocupação com relação a espécie humana, com o meio no qual sobrevive essa espécie, meio geográfico, clima, hidrografia que caracterizam e circunscrevem um meio que também é artificial - as cidades, influenciando de modo singular a vida da população.

Nessa perspectiva, observa-se que o foco da biopolítica é de fato as populações, assim como, os elementos que se pretende intervir são fenômenos coletivos, que só ganham pertinência quando analisados no nível da coletivi- 
dade. Para Foucault (2010, p. 206-207) a biopolítica terá como foco fenômenos aleatórios, que acometem uma população considerada em sua duração, acontecimentos em série que só fazem sentido quando analisados ao longo de um período de tempo. Ao passo que se busca a previsibilidade e se compreender a imprevisibilidade de determinados fenômenos, como acidentes incapacitantes, por exemplo, desenvolve-se novos mecanismos muito mais sutis do que os que se haviam instaurado até aqui, surgem os mecanismos de seguros, poupança individual e coletiva, seguridade, dentre outros.

As tecnologias geradas pela biopolítica também diferem dos mecanismos desenvolvidos até então, pois buscam as estimativas estatísticas, as previsões, medidas globais e possibilidades de intervenção e controle sobre os determinantes desses fenômenos globais. Nesse contexto, as intervenções não são realizadas no nível individual, no nível do detalhe, destacam-se mecanismos globais de ação, estados globais de equilíbrio, modos de assegurar sobre o homem-espécie uma regulamentação.

Esse poder, que inverte a lógica do direito soberano, segundo Foucault (2010, p. 214-215), permitindo agora a vida ou deixando a morte acontecer, cria novos e sofisticados mecanismos para agir sobre a população, e é aqui que Foucault desenvolve um de seus conceitos mais interessantes, o racismo de Estado. O racismo de Estado surge como um mecanismo que buscará exercer a função da morte em um sistema político centrado no biopoder, possui algumas funções específicas, dentre as quais destacamos: (a) promover o corte entre o que deve viver e o que deve morrer; (b) produzir uma relação positiva, permitirá estabelecer entre a vida de uma pessoa e a morte da outra uma relação que não é militar, mas uma relação de caráter biológico:

\footnotetext{
A morte do outro, não é simplesmente a minha vida, na medida em que seria minha segurança pessoal; a morte do outro, a morte da raça ruim, da raça inferior (ou do degenerado, ou do anormal), é o que vai deixar a vida em geral mais sadia; mais sadia e mais pura. (FOUCAULT, 2010, p. 215)
}

Nesse contexto, o direito de matar, na lógica do biopoder é exercido pelo racismo de Estado. Foucault (2010, p. 216-217) deixa claro que ao falar em morte, nesse contexto, não fala exatamente do assassinato direto, mas também do indireto, como a exposição à morte, a multiplicação de alguns riscos de morte, a morte política, a expulsão, a rejeição, etc. Nesse contexto, os Estados exerceram o racismo de Estado em suas variadas faces nos processos de colonização, de dominação, mas não apenas com relação a outros povos, como também através da exposição de seus próprios cidadãos a morte, como no caso das guerras. Foucault acredita que o racismo de Estado assegura a função de morte 
na economia do biopoder, ao passo em que se é membro de uma pluralidade de vida, a morte dos mais fracos, permite o fortalecimento da própria pessoa.

O biopoder também é exercido a partir do controle sobre o território. A soberania, a disciplina e a segurança fazem do território instrumento para o exercício do poder, sendo a soberania exercida no interior do território, já o controle disciplinar sobre os territórios aparece na sujeição dos corpos, como exemplo, temos os procedimentos de segregação dos doentes, separação e delimitação frente às outras esferas da população, sob o risco de contágio. A partir do século XVIII destaca-se a emergência dos dispositivos de segurança no interior seja de mecanismos de controle social, seja em mecanismos que tem como "função modificar em algo o destino biológico da espécie" (FOUCAULT, 2008, p. 15), tendo como um de seus principais aliados o controle estatístico dos fenômenos epidêmicos e endêmicos que poderão se abater sobre uma dada população (FOUCAULT, 2008, p. 14-17).

Para Foucault (2008, p. 22-28) a questão do ordenamento do espaço territorial compreende pontos em comum entre a soberania, a disciplina e a segurança. Enquanto a soberania é estabelecida no interior do território total, a disciplina e a segurança se exercem em território fragmentado, calculadamente repartido. . Ao longo dos séculos XVII, XVIII, XIX o controle da disposição e organização espacial das cidades serviu a tentativas de controle das pessoas e das populações. A soberania com o intuito de capitalizar o território, focaliza a sede do governo; a disciplina possui na distribuição arquitetônica dos espaços a forma de demarcar seu controle e suas hierarquias; já a segurança cria um ambiente em função dos acontecimentos em séries, "séries que vai ser preciso regularizar num contexto multivalente e transformável" (FOUCAULT, 2008, p. 27).

Ainda no que diz respeito ao debate, Foucault (2008, p. 28) chama atenção para procedimentos de naturalização da espécie humana em processos de urbanização que são artificiais. Para o autor, esse meio histórico-natural torna-se alvo da intervenção do poder, principalmente da ação daquilo que ele chama de biopolítica ou biopoder.

E são justamente as cidades um dos principais locais para o exercício da arte de governar. Foucault (2008, p. 143) trata sobre as estratégias de governo e suas mudanças ao longo da história, sobre como as mesmas estão atreladas ao exercício do poder. $\mathrm{O}$ advento do conhecimento estatístico das populações também produziu modificações profundas na forma de governo, novamente não substituindo o governo de soberania ou disciplinar, mas agregando elementos e formando o que se caracteriza como um "triângulo", constituído pela soberania, pela disciplina e pela gestão governamental, tendo está última a população como principal alvo e os dispositivos de segurança como principais mecanismos. 
Nesse sentido, Foucault (2008, p. 143-144) desenvolve o conceito de governamentalidade, para falar dos elementos que estão envolvidos no governo das populações, definindo-a através de três processos. O primeiro seria o bloco composto por instituições, metodologias, análises, estratégias e cálculos que possibilitam que uma forma singular de poder seja exercida sobre a população, atuando através da economia política e sendo instrumentalizada pelos dispositivos de segurança.

Para o autor, a governamentalidade também pode ser compreendida como uma linha de forças que teve como foco o governo, um tipo de poder, desenvolvendo uma série de conhecimentos e técnicas para o controle da população. Por fim, também podemos compreendê-la como "o resultado do processo pelo qual o Estado de justiça da Idade Média, que nos séculos XV e XVI se tornou o Estado Administrativo, viu-se pouco a pouco governamentalizado" (FOUCAULT, 2008, p.144)

A ideia de dispositivo é bastante utilizada pelo autor ao longo de sua obra e para explicitação de alguns mecanismos da governamentalidade, sendo descrita por ele como:

[...] um conjunto decididamente heterogêneo que engloba dis-
cursos, instituições, organizações arquitetônicas, decisões re-
gulamentares, leis,medidas administrativas, enunciados cientí-
ficos, proposições filosóficas, morais, filantrópicas. Em suma, o
dito e o não dito são os elementos do dispositivo. O dispositivo
é a rede que se pode estabelecer entre estes elementos. (FOU-
CAULT, 1993, p. 244)

Os dispositivos de segurança são exemplificados por Foucault (2008, p. 58-59) quando vem tratar da política de circulação de cereais e do modo como algumas temáticas, tais como a questão da escassez alimentar, são radicalmente modificadas ao passo que novos modelos econômicos se solidificam no contexto das cidades. À medida que a questão da população configura-se como ponto emergente, a segurança apresenta-se como dispositivo que irá integrar diversos elementos "como a produção, a psicologia, os comportamentos, as maneiras de fazer dos produtores, dos compradores, dos consumidores, dos importadores, dos exportadores, integra-se ao mercado mundial." (FOUCAULT 2008, p. 59). Nesse sentido a segurança assume um grande caráter regulador.

Os elementos contextuais trabalhados até o momento serão fundamentais para avançarmos em nosso texto, pois a partir dos mesmos buscaremos lançar nossa compreensão sobre os modelos de riscos de desastres produzidos e trabalhados no sistema de Proteção e Defesa Civil. Para isso, no tópico a seguir faremos uma breve descrição da metodologia desenvolvida no presente estudo. 


\section{Método}

O presente estudo está inserido em uma metodologia qualitativa, com orientação do construcionismo em psicologia social. Defendemos que a dimensão de complexidade e multiplicidade que se aplica às pesquisas qualitativas precisa ser descrita pelo(a) pesquisador(a) de modo claro e com riqueza de detalhes, pois como nos aponta Spink e Lima (2004, p. 102) as pesquisas qualitativas alcançam seu rigor muito mais pela capacidade de comunicar as estratégias, escolhas e ideias do(a) pesquisador(a) do que por sua capacidade de replicabilidade.

Conforme destacado anteriormente, o presente estudo faz parte de uma pesquisa maior,em construção. Nesse sentido, para realização da presente pesquisa foram selecionados dois grupos de documentos, reunidos e catalogados no período de maio a julho de 2014. O primeiro grupo corresponde a documentos acadêmicos e páginas da internet selecionados por descreverem o histórico de surgimento da defesa da Defesa Civil no Brasil, eventos disparadores, objetivos de cada órgão, foco de trabalho, entre outros elementos que nos auxiliassem a compreender o modelo de risco de desastres proposto pela defesa civil nacional.

O segundo grupo foi composto por dois documentos: O Plano Nacional de Gestão de Risco e Resposta a Desastres Naturais, lançado pelo governo federal como propostas de ações para 2012-2014 e a Lei n ${ }^{\circ} 12.608$ de 2012 que trata da Política Nacional de Proteção e Defesa Civil - PNPDEC. Tais documentos, sinalizam atualmente como deve ocorrer o trabalho na Defesa Civil, focos e proposta de ação, podendo nos fornecer uma proposta atual sobre quais os conceitos de riscos de desastre são utilizados pela Defesa civil e sobre como estes conceitos circulam e atuam no contexto pesquisado. Os dois grupos de produções textuais foram analisados sob a perspectiva da análise do discurso.

A proposta de análise do discurso desenvolvida no presente texto compreende a linguagem não como um meio neutro de refletir ou descrever o mundo, sendo o discurso considerado como elemento central da construção social (GILL, 2003, p. 244). De acordo com Potter e Wetherell (1992, p. 9) na proposta da análise do discurso os elementos discursivos são tratados como um potente meio orientado para a ação, e não um canal transparente de informação. Para os autores o termo análise do discurso engloba a análise de diversas manifestações discursivas, como entrevistas, textos e conversas realizadas no cotidiano, por exemplo.

A análise do discurso empreendida em nosso estudo considera as relações saber/ poder/verdade. Compreendendo o órgão defesa civil como parte de um 
dispositivo de segurança (FOUCAULT, 2008, p. 59) buscaremos identificar e analisar, nas produções discursivas catalogadas:a gramática dos riscos, contexto histórico da institucionalização da defesa civil, características e missão dos órgãos competentes, orientações para ações dos(as) técnicos(as) e da população alvo da política, usos dos saberes peritos, produções de verdade sobre as populações consideradas em situação de risco. Interessa compreender como cada elemento contribui para formação de um modelo de risco de desastres.

Tendo em vista os objetivos do presente estudo todos os documentos coletados foram lidos e relidos com o intuito de construirmos compreensões sobre os textos e documentos em análise. Para Minayo (2012, p. 623-624) ordenar o material encontrado no campo e "impregnar-se" do mesmo na tentativa de compreendê-lo são processos fundamentais para uma análise qualitativa. A tipificação foi fundamental para organização dos dados encontrados, que foram recortados e agrupados na busca de compreendermos o modelo de risco de desastres que circula no contexto do atual sistema de Proteção e Defesa Civil do Brasil.

\section{Resultados e discussão}

Tendo em vista os elementos que foram expostos até o presente momento, tendo como referencial a pesquisa qualitativa em psicologia social, passaremos agora a análise de alguns documentos, leis e propostas de ação que tratam das temáticas de Proteção e Defesa civil e de nossas observações sobre o modelo de riscos de desastre que está presente nesses documentos.

Em recente dissertação publicada pela PUC-SP Tavanti (2013, p. 47) divulga os dados de uma pesquisa realizada pelo Núcleo de Práticas Discursivas e Produção de Sentidos sobre uma análise histórica da legislação brasileira e suas intersecções com a problemática de desastres entre os anos de 1824 até 1988 , segundo os resultados da pesquisa praticamente todos os documentos legislativos pesquisados citavam termos como:

[...]incêndio, inundação, socorros públicos [1824]; socorros,
calamidade pública, desastres [1891]; seca, defesa permanente,
desastres, calamidade pública, assistência econômica [1934];
desastres, seca, calamidade pública, assistência à população
atingida [1964]; desastres, defesa permanente, calamidade pú-
blica, seca, inundação [1967]; e, desastres, socorro, calamida-
de pública, indústria nuclear, Estado de Defesa, Defesa Civil
[1988]. (TAVANTI, 2013, p. 47)

Como podemos observar a preocupação com a problemática relativa aos desastres não é recente na história da legislação brasileira. Mesmo sendo ape- 
nas no século XX quando se começa a falar propriamente em defesa civil, observamos que inundações, socorros, calamidades são palavras que ganharam foco legal muito antes desse período.

No Brasil foi no período relativo a Segunda Guerra Mundial, precisamente em 1942, na ocasião do afundamento de embarcações militares pelo submarino Alemão U507, que se começou a pensar formalmente em uma instituição de Defesa Civil, chamado Serviço de Defesa Passiva Antiaérea.Observa-se, nesse contexto um surgimento militarizado das questões relativas a defesa civil nacional. Sendo apenas na década de 60 , em decorrência de fortes chuvas que devastaram a região sudeste do Brasil, que a Defesa Civil nacional começou a configurar seu discurso em torno das questões climáticas ${ }^{1}$.

Percebe-se nesse contexto, que a preocupação com eventuais questões climáticas que pudessem assolar a população levou as autoridades governamentais a criar uma série de iniciativas que focavam combater o problema. Data da década de 60 a criação do Plano Diretor de Defesa Civil do Estado da Guanabara; criação da Primeira Defesa Civil, estadual também no estado da Guanabara; criação das Coordenadorias Regionais de Defesa Civil - REDEC. Tendo ainda no final dos anos 60 sido instituído o Fundo Especial para Calamidades Públicas (FUNCAP) e o Grupo Especial para Assuntos de Calamidades Públicas - GEACAP ambos com objetivo de prestar assistência e defesa permanente contra as calamidades públicas.

A partir dessas iniciativas observamos o surgimento de políticas de Defesa Civil voltadas para o trabalho de questões pontuais, ainda numa lógica assistencialista e primordialmente voltada para o pós-desastre. Apenas em 1988, com o Decreto $n^{\circ} 97.274$, de 16/12/1988, observa-se uma preocupação com a prevenção de desastres. Tendo em 1990 a ONU decretado a Década Internacional para Redução dos Desastres Naturais (DIRDN), para atender a referida iniciativa o Brasil elaborou a Política Nacional de Defesa Civil - PNDC estruturada em quatro eixos: prevenção, preparação, resposta e reconstrução. Sendo em toda a década de 2000 o foco de atuação da SEDEC (Secretaria Especial de Defesa Civil) o gerenciamento dos desastres e a capacitação de agentes locais de defesa civil.

Em 2009 foi realizada a $1^{\text {a }}$ Conferência Nacional de Defesa Civil e Assistência Humanitária cujos 1.500 delegados representantes dos Estados, Distrito Federal e Municípios brasileiros, destacaram a importância do fortalecimento das instituições de Defesa Civil municipais. Ao final da etapa nacional foram aprovadas 104 diretrizes. A segunda década do século XXI caracteriza-se pela retomada dos princípios

$1 \quad$ http://www.integracao.gov.br/historico-sedec,acesso em 05 de dezembro de 2013. 
de redução de desastres, com a implantação do Planejamento Nacional para Gestão de Riscos - PNGR, a construção do Banco de Dados de Registros de Desastres e do Atlas Brasileiro de Desastres Naturais, a criação da Política Nacional de Proteção e Defesa Civil - PNDEC, a organização do Sistema Nacional de Proteção Civil - SINPDEC, entre outras ações de gerenciamento de riscos e desastres. Em dezembro de 2014 ocorreu a Segunda Conferência Nacional de Proteção e Defesa Civil, com um intuito de fortalecer a nova política nacional de Defesa Civil e propor novas diretrizes.

Segundo o Decreto $\mathrm{n}^{\circ} 7.257$, de 4 de Agosto de 2010. Defesa Civil é o conjunto de ações preventivas, de socorro, assistenciais e recuperativas destinadas a evitar desastres, minimizar seus impactos para a população e restabelecer o cotidiano social.

No Estado de Pernambuco a defesa civil surge inicialmente por meio do Decreto Estadual no 2.345, de 1971, chamando-se Comissão Estadual de Acompanhamento às Vítimas das Calamidades Públicas, sendo subordinada à Secretaria Assistente, posteriormente passando a chamar-se Comissão de Defesa Civil do Estado de Pernambuco - CODECIPE, através do Decreto $n^{\circ}$ 2.372, também de 1971. Segundo informações do governo do estado de Pernambuco ${ }^{2}$ compete a CODECIPE responsabilizar-se pela assistência de defesa civil às pessoas que, por ventura, sejam atingidas por fenômenos naturais, a exemplo de secas e inundações, buscará também prever recursos orçamentários próprios necessários às ações assistenciais, de recuperação ou preventivas, como contrapartida às transferências de recursos da União, na forma da legislação vigente.

Na capital do estado de Pernambuco, Recife, o marco fundador da defesa civil ocorreu em 1986 com a criação da Comissão de Defesa Civil, tendo como foco a atuação em situações pontuais de emergência ou desastres. Foi apenas em 2004, a partir do Decreto $n^{0} 20.572$ que o órgão passou a ter uma estrutura de funcionamento permanente, tornando-se uma Coordenadoria de Defesa Civil (Codecir), atuando com o princípio básico da prevenção de acidentes. Em 2013 a então Codecir transformou-se em Secretaria Executiva de Defesa Civil (SEDEC), com o objetivo de uma proposta mais autônoma de desenvolvimento e trabalho.

Percebemos a partir dessa análise inicial que pouco se buscou compreender ao longo das referidas iniciativas sobre os elementos que subvertiam as intempéries climáticas em grandes catástrofes ao longo da história de nosso país. Será que de fato o clima/natureza é o maior causador de transtornos e danos nas situações de calamidade? Será que de fato todas as camadas da po-

2 Fonte: http://www.pe.gov.br/orgaos/codecipe-coordenadoria-de-defesa-civil-de-pernambuco/ acesso em 17 de julho de 2014 . 
pulação são atingidas de igual modo pelos desastres naturais? Não é preciso ir muito longe para responder as referidas perguntas, basta observar as capas dos jornais que estampam as imagens das cidades e pessoas atingidas pelos desastres brasileiros, a maioria são pessoas pobres, que habitam terrenos ilegais e irregulares, com edificações improvisadas e quase que totalmente desprovidos da assistência do Estado.

Não estamos afirmando aqui que as classes mais favorecidas não são afetadas pelas situações de emergência que são foco da defesa civil, havia vítimas de distintas classes sociais nas enxurradas que atingiram a região serrana do Rio de Janeiro em 2011, por exemplo. Observamos no entanto, que para as classes menos favorecidas que habitam as periferias brasileiras tais situações ganham tom de rotina e começam a fazer parte de um cenário habitual. Como nos alerta Freitas et al. (2012, p. 1578-1579) tais desastres extensivos, são facilmente incorporados ao dia-a-dia de uma população, fazendo parte do cotidiano daqueles que devem gerenciar suas vidas e o lugar comum de estar em risco.

Nesse sentido, nos questionamos sobre porque as autoridades governamentais insistem em perpetuar o discurso do risco associado às questões climáticas. Quais jogos de saber e de poder perpassam esse universo? Como as construções discursivas em torno da temática de riscos de desastres posicionam a população como vulnerável às questões climáticas e em seu limite culpabilizam essa mesma população pelos riscos que vivenciam?

Observamos a partir dos elementos expostos até o momento, que a questão climática, dos desastres associados aos fenômenos da natureza, foco das ações da defesa civil e apresentada como motivadora de seu surgimento, possui uma outra função para com o Estado, encobrir sua ausência frente as necessidades habitacionais da população pobre. Tal estratégia de governamentalidade, como nos indica Foucault (2008, p. 143-144), apresenta a natureza como uma espécie de "bode expiatório", que tira o foco da negligência do Estado para com as vulnerabilidades da população e centra a problemática em elementos que são imprevisíveis, os fenômenos da natureza.

Para aprofundarmos um pouco mais esse debate, faremos uma breve análise de dois documentos recentes que trazem diretrizes de ação para os(as) profissionais que atuam de modo direto e indireto com a temática de defesa civil: O Plano Nacional de Gestão de Risco e Resposta a Desastres Naturais, lançado pelo governo federal como propostas de ações para 2012-2014 e a Lei n $12.608 / 2012$ que institui a Política Nacional de Proteção e Defesa Civil PNPDEC.

O Plano Nacional de Gestão de Risco e Resposta a Desastres Naturais lançado em agosto de 2012 possui como objetivo principal "garantir segu- 
rança às populações que vivem em áreas suscetíveis a ocorrências de desastres naturais" ${ }^{3}$, observa-se que o texto do documento, em nenhum momento problematiza a definição desastres "naturais", colocando como foco de suas ações quatro eixos: Prevenção (Obras Estruturantes), Mapeamento (Áreas de Risco), Monitoramento e Alerta (Estruturação da Rede Nacional), e Resposta (Socorro, assistência e reconstrução). O que a princípio pode ser observado como o ordenamento de uma questão estrutural bastante ampla, também pode ser interpretado como uma luta do governo contra a natureza produtora de desastres, pois se os desastres são naturais não nos cabe preveni-los.Observe que mesmo as questões que tratam de prevenção são ligadas a relação de obras estruturantes, ou seja, obras que visam conter os fenômenos naturais. Não se problematiza, por exemplo, a forma como nosso território está ordenado, restringindo cada vez mais a população de baixa renda às áreas de extrema vulnerabilidade, como morros, planícies alagáveis ou mesmo para baixo das marquises e viadutos. Parece que pensar o planejamento urbano é um elemento bem distante das metas do governo para os próximos anos.

Foucault (2008, p. 58-60) nos adverte que a questão do ordenamento territorial foi durante muito tempo pensada como forma de controle das populações. Questões como insuficiência de alimentos, e até mesmo a definição do que é risco já são apontados pelo autor como instrumentos de governamentalidade, de controle das cidades e da população. Diante do que foi exposto até o presente momento, como poderíamos pensar a lógica de ordenamento do território nas cidades brasileiras? Observamos que os textos produzidos para regulamentar as ações em defesa civil apresentam muitos elementos que nos auxiliar a compreender a problemática proposta.

Continuando nossas análises buscaremos agora refletir sobre a Lei $\mathrm{n}^{\circ}$ 12.608/2012 que trata da Política Nacional de Proteção e Defesa Civil - PNPDEC. Nossa análise buscou em vários trechos da lei compreender as definições de risco de desastres ou do que seria estar em risco, assim como, das principais propostas para trabalhar a referida situação.

A primeira referência explicita do que seriam os agentes de risco alvo da

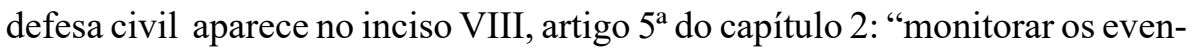
tos meteorológicos, hidrológicos, geológicos, biológicos, nucleares, químicos e outros potencialmente causadores de desastres". Observamos claramente o elemento climático como foco central das ações que devem ser monitoradas pela defesa civil. Mesmo a questão da ocupação do solo aparecendo no texto da lei, é posta de modo a evitar o desgaste natural, a evitar intercorrências

3 Os referidos objetivos, não foram incorporados ao texto oficial de divulgação do plano, mas aparecem como

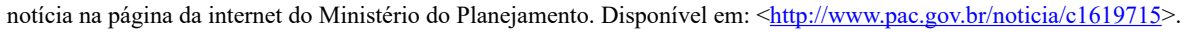
Acesso em 29 de outubro de 2014. 
climáticas: "combater a ocupação de áreas ambientalmente vulneráveis e de risco e promover a realocação da população residente nessas áreas" (Capítulo 2, artigo $5^{\circ}$, inciso XI).

A população aparece ao longo do texto como aquela que ocupa áreas suscetíveis a riscos climáticos, geralmente por falta de conhecimento dos riscos que podem enfrentar,como observamos no trecho que segue: "orientar as comunidades a adotar comportamentos adequados de prevenção e de resposta em situação de desastre e promover a autoproteção" (Capítulo 2, artigo $5^{\circ}$, inciso XI). A mesma ideia apresenta-se com o acréscimo que a lei faz ao artigo 26 da lei de Diretrizes e Bases da Educação Nacional (Lei no 9.394/1996) com o parágrafo 7: "Os currículos do ensino fundamental e médio devem incluir os princípios da proteção e defesa civil e a educação ambiental de forma integrada aos conteúdos obrigatórios."

Não afirmamos que as questões da educação ambiental e de proteção e defesa civil não são pertinentes ao debate em escolas e comunidades, mas acreditamos que as implicações que envolvem a problemática das populações no contexto das emergências e desastres vão muito além da questão "eduque-se para não expor-se ou provocar o risco". Observamos aqui uma lógica perversa para com a população, mais uma vez o Sistema de Proteção e Defesa Civil atua como parte de um dispositivo de segurança (FOUCAULT, 2008, p. 144), que além de participar do jogo que irá expulsar a população para os núcleos de pobreza, irá responsabilizar essas pessoas pela garantia de segurança nesses espaços.

O foco nos riscos de desastres naturais aparece de modo tão forte na Lei $n^{\circ} 12.608 / 2012$ que quando propõe os elementos mínimos para elaboração de um Plano Nacional de Proteção e Defesa Civil, apenas as questões relativas a tais elementos são consideradas:

\footnotetext{
I - a identificação dos riscos de desastres nas regiões geográficas e grandes bacias hidrográficas do País; e

II - as diretrizes de ação governamental de proteção e defesa civil no âmbito nacional e regional, em especial quanto à rede de monitoramento meteorológico, hidrológico e geológico e dos riscos biológicos, nucleares e químicos e à produção de alertas antecipados das regiões com risco de desastres. (Capítulo 2, sessão 2 , incisos I e II, do § 1)
}

A questão do desastre natural aparece de modo contundente ao longo de todo o texto da lei, reforçando a lógica de que no Brasil os desastres são causados por intempéries climáticas e que por conseguinte, as políticas de proteção de defesa civil devem estruturar-se nesse viés. Define-se o risco, com foco 
nas questões "naturais", definem-se as ações, monitorar a incidência desses elementos e estimula-se a educação da população para reconhecer o risco, evitá-lo ou mesmo não provocá-lo.

Foucault (2008, p. 14-17) sinaliza que a busca por compreender fenômenos aleatórios que acometem as populações, no caso da defesa civil, as questões climáticas, fazem parte de mecanismos de controle sobre as populações, possibilitando a intervenção sobre fenômenos coletivos. Cria-se um contexto especifico, as áreas de risco, uma problemática específica, a questão ambiental e por conseguinte, todo um conjunto de práticas e saberes destinados a controlar esse novo universo agora circunscrito, o Sistema de Proteção e Defesa Civil.

\section{Conclusões}

As análises realizadas até o presente momento não se esgotam aqui, certamente precisaremos avançar ainda mais na investigação e debate de outros documentos, trazendo novos elementos discursivos para compor nossas análises. Contudo, nossas compreensões iniciais nos levaram a questionamentos, que motivam a continuidade dos estudos sobre o tema.

Tendo em vista o que foi debatido até o presente momento sobre a questão do risco, levando-se em consideração a análise desenvolvida a partir das leituras de Michel Foucault sobre a problemática do controle das populações no contexto do conhecimento estatístico e das tecnologias desenvolvidas pelo biopoder, nos questionamos a que serve essa parcela da população que hoje se torna alvo do gerenciamento do risco no contexto da proteção e defesa civil? Inserir os pobres na política de gestão dos riscos e desastres funciona estrategicamente para mantê-los distante dos direitos sociais? Até que ponto ao focar a questão climática e ambiental nas políticas de defesa civil o Estado brasileiro não está promovendo o racismo de Estado para decidir quem deve fazer viver e quem deve deixar morrer?As legislações parecem dizer, fome, desemprego, falta de moradia não são produtores de desastre, os riscos são provocados pela natureza, portanto essa deve ser monitorada, compreendida e domesticada.

Ao refletirmos sobre o atual contexto de urbanização das cidades brasileiras, sob a perspectiva de alguns conceitos anteriormente debatidos observamos um Sistema de Proteção e Defesa Civil que se apresenta como elemento de um dispositivo de segurança dentro das estratégias de governamentalidade do Estado. No contexto da biopolítica das populações os dispositivos de segurança são mecanismos sofisticados que incidem sobre a população, conhecem suas necessidades, suas características, para impor seu controle. Apresenta-se uma lógica sofisticada e perversa que define o que é risco e em nome da segurança culpabiliza e exclui. 
Nesse sentido, nos questionamos se de fato as ações de Proteção e Defesa Civil buscam combater os "desastres naturais", ou se o gerenciamento do risco não poderia ser, na grande maioria dos casos, substituído pelo termo gerenciamento da ausência de políticas sociais? A defesa civil gerencia o risco em locais onde não há rede de esgotos, coleta de lixo, água encanada, onde a maioria das casas não é de tijolos, onde não há empregos, áreas de lazer. Gerenciamento do risco de desastres naturais ou gerenciamento da pobreza?

A análise do material selecionado permitiu-nos localizar jogos de saber -poder que perpassam e contextualizam o dispositivo de segurança, a rede de relações estabelecida para configurar o modelo de risco de desastre proposto por esse dispositivo. Identificamos a prevalência de discursos voltados para as questões climáticas, o posicionamento da população pobre como pertencente a grupos que se expõe ao risco, que precisam ser orientados e educados por saberes peritos que naturalizam as desigualdades sociais.

Não podemos deixar de reforçar a ideia de que as pessoas não ocupam esse espaço por opção, como nos alerta Beck (2011, p. 23-25) os modelos de modernização contemporâneos produzem riscos, no caso do Brasil e de outros países em desenvolvimento também produz pobreza e exclusão. $\mathrm{O}$ processo de modernização das cidades brasileiras tem produzido espaços de pobreza, expulsando os menos favorecidos para as áreas de morro e construções irregulares, pobreza que tem sido monitorada de perto pelos órgãos de defesa civil, porém muitas de suas consequências - deslizamentos provocados pela falta de saneamento, de obras de drenagem - tem se travestido em questão ambiental.

Foucault (2010, p. 202), nos alerta que na lógica do biopoder caberá ao soberano, no nosso caso o Estado, "fazer viver ou deixar morrer", abandonar a população a própria sorte, não promover políticas sociais de equidade são modos de exercer esse direito. Quando uma política de governo permite, ou mesmo favorece a produção de bolsões de pobreza, quando o que diferencia uma área de risco e um local seguro é apenas uma obra pública, o Estado está definindo quem fará viver e quem deixará morrer.

Os processos de urbanização impostos pela biopolítica das populações (FOUCAULT, 2008, p. 29) engendram a naturalização da espécie humana em estruturas de urbanização artificiais. Será que chove mais nos morros das metrópoles do que nos bairros nobres com saneamento e projeto arquitetônico/ estruturais? Não, certamente não, mas há nos primeiros espaços o descaso, a exclusão, a falta de um olhar efetivo por parte dos governantes.

A forma como um povo ocupa os diversos espaços das cidades diz muito das políticas que são para eles propostas, observamos ao longo do presente 
texto que em vários momentos da história pôde-se registrar a busca do controle populacional pelo modo como as cidades foram edificadas. Nas grandes metrópoles brasileiras, para as classes menos favorecidas são reservados os guetos, os morros e as áreas sujeitas às sazonalidades das marés. Ao mesmo tempo em que as políticas econômicas excluem as populações para as periferias pobres, o governo sinaliza os referidos espaços como espaços de risco, que precisam de cuidados e de profissionais especializados. Cria-se um olhar e uma linguagem referentes às vulnerabilidades as quais estão expostos tais grupos de "risco".

\section{Referências}

ALVES, R. B.; LACERDA, M. A. C.; LEGAL, E. J. A Atuação do Psicólogo diante dos Desastres Naturais : uma Revisão. Psicologia em Estudo, Maringá, v. 17, n. 2, p. 307-315, abr./ jun. 2012.

BECK, U. Sociedade de Risco: rumo a uma outra modernidade. 2. ed. São Paulo: Ed. 34, 2011. $384 \mathrm{p}$.

BRASIL. (Ministério do Planejamento). Plano Nacional de Gestão de Risco e Resposta a Desastres Naturais. Brasília-DF, 2012. Disponível em: < http://www.pac.gov.br/pub/up/relatorio/d0d2a5b6f24df2fea75e7f5401c70e0d.pdf >. Acesso em: 04 jul. 2014.

BRASIL. Lei no 12.608, de 10 de abril de 2012. Política Nacional de Proteção e Defesa Civil - PNPDEC. Diário Oficial [da] República Federativa do Brasil. Poder Executivo. BrasíliaDF, 2012. Disponível em: < http://www.planalto.gov.br/ccivil_03/_Ato2011-2014/2012/Lei/ L12608.htm >Acesso em: 03 fev. 2015.

CARDOSO, T. A. O.; COSTA, F. G.; NAVARRO, M. B. M. A. Biossegurança e desastres: conceitos, prevenção, saúde pública e manejo de cadáveres. Revista de Saúde Coletiva, Rio de Janeiro, v. 22, n. 4, p. 1523-1542, 2012.

CEPED. Centro de estudos e pesquisas em emergências e desastres em saúde. Atlas Brasileiro de Desastres Naturais 1991-2010: Volume Pernambuco. Florianópolis: CEPED/UFSC, 2011. $67 \mathrm{p}$.

CEPED. Centro de estudos e pesquisas em emergências e desastres em saúde. Comunicação de riscos e de desastres. Curso a distância / Centro Universitário de Estudos e Pesquisas sobre Desastres. Florianópolis: CEPED, 2010. 183 p.

CEPEDES/FIOCRUZ. Centro de estudos e pesquisas em emergências e desastres em saúde. O mundo hoje e os desastres. Disponível em: http://andromeda.ensp.fiocruz.br/desastres/content/o-mundo-hoje-e-os-desastres . Acesso em: 25 mar. 2013.

FERREIRA, A. B. H. Novo Dicionário da Língua Portuguesa. 4. ed. Rio de Janeiro: Positivo, 2010. 2272 p.

FOUCAULT, M. Microfísica do Poder. 11. ed. Rio de Janeiro: Graal, 1993. 432 p. 
SILVA, Juliana Catarine Barbosa da, MENEZES, Jaileila de Araújo. O risco de desastre e as cidades...

FOUCAULT, M. Segurança, Território, População. São Paulo: Martins Fontes, 2008. 572 p.

FOUCAULT, M. Em defesa da Sociedade. 2. ed. São Paulo: Martins Fontes, 2010. 269 p.

FRANCO, M. H. P. Atendimento psicológicos para emergências em avião: a teoria revista na prática. Estudos de Psicologia, Natal, v. 10, n. 2, p. 177-180, maio/ago., 2005.

FREITAS, C. M.; CARVALHO, M. L.; XIMENES, E. F.; ARRAES, E. F.; GOMES, J. O. Vulnerabilidade socioambiental, redução de riscos de desastres e construção da resiliência - lições do terremoto no Haiti e das chuvas fortes na Região Serrana, Brasil. Ciência\&Saúde Coletiva, Rio de Janeiro, v. 17, n. 6, p. 1577-1586, 2012.

GILL, R. Análise do Discurso. In GASKELL, G. (Org.). Pesquisa qualitativa com texto, imagem e som. 2. ed. Petrópolis, RJ: Vozes, 2002, p. 244 - 270.

IBGE. Censo Demográfico 2010 - Resultado do Universo - Aglomerados Subnormais. (anexo_tab1). 2010. Disponível em: $\leq$ http://downloads.ibge.gov.br/downloads_estatisticas.htm>. Acesso em: 25 ago. 2016.

LAROUSSE. Dicionário da Língua Portuguesa. São Paulo: Moderna, 1992. 1176 p.

MATTEDI, A. M. A Abordagem Psicológica da Problemática dos Desastres: um Desafio Cognitivo e Profissional para a Psicologia. Psicologia: Ciência e Profissão, Brasília, v. 28, n. 1, p. 162-173. 2008.

MINAYO, M. C. S. Análise qualitativa: teoria, passos e fidedignidade. Ciência \& Saúde Coletiva, Rio de Janeiro, v. 17, n. 3, p. 621-626. mar. 2012.

PAULINO, J. A. ; LOPES, R. F. F. Relação entre Percepção e Comportamento de Risco e Níveis de Habilidades Cognitivas em um Grupo de Adolescentes em Situação de Vulnerabilidade Social. Psicologia: Ciência e Profissional, Brasília-DF, v. 30, n. 4, p. 752-765. 2010.

POTTER, J.; WETHEREll, M. Discourse and Social Psychology: beyond attitudes and behaviour. 2. ed. London: Sage, 1992. 216 p.

SPINK, M. J.; LIMA, H. Rigor e Visibilidade: a explicação dos passos da interpretação. In: Spink, M. J. (Org.). Práticas discursivas e produção de sentidos no cotidiano: aproximações teóricas e metodológicas. 3. ed. São Paulo: Cortez, 2004, p. 93-122.

SPINK, M. J.; PEREIRA, A. B.; BURIM, L. B.; SILVA, M. A.; DIODATO, P. R. (2008) Usos do Glossário do Risco em Revistas: contrastando "Tempo" e "Públicos". Psicologia: Reflexão e Crítica, Porto Alegre, v. 21, n. 1, p. 1-10. 2008. Disponível em: http://www.scielo.br/pdf/prc/ v21n1/a01v21n1.pdf. Acesso em: 10 maio 2015.

TAVANTI, R. M. Risco, desastre e prevenção: um estudo sobre estratégias coletivas na ótica de adolescentes moradores do Bairro do Jaçanã - São Paulo/SP. 2013. Dissertação de Mestrado, Programa de Pós-graduação em Psicologia Social, Pontifícia Universidade Católica de São Paulo, SP, 2013.

VALENCIO, N.; SIENA, M.; MARCHEZINE, V.; GONÇALVES, J. C. (Orgs.). Sociologia dos Desastres: construção, interfaces e perspectivas no Brasil. São Carlos/SP: Rima, 2009. $280 \mathrm{p}$. 
Submissão: 22/08/2015

Revisão: 23/08/2016

Aceite: $31 / 10 / 2016$

Juliana Catarine Barbosa da Silva é doutoranda do Programa de Pós-graduação em Psicologia da Universidade Federal de Pernambuco. Mestra em Psicologia pela mesma Universidade. Psicóloga da Prefeitura Municipal do Recife.

E-mail: jucatarine@gmail.com

Jaileila de Araújo Menezes possui graduação em Psicologia pela Universidade Federal do Ceará (1997), mestrado em Psicologia pela Universidade Federal do Rio de Janeiro (1999) e doutorado em Psicologia pela Universidade Federal do Rio de Janeiro (2004). Atualmente é professora associada I da Universidade Federal de Pernambuco. Tem experiência na área de Psicologia, atuando principalmente nos seguintes temas: participação política juvenil, juventude e projeto de vida, juventude e movimentos sociais, subjetivação de crianças e adolescentes na contemporaneidade.

E-mail: jaileila.araujo@gmail.com 